\title{
Nova Orleans não é aqui?
}

\section{Micael Herschmann e Cíntia Sanmartin Fernandes}

\section{Resumo}

Tomando especialmente como referência não só as obras de Negus, Maffesoli, Deleuze, Guattari, Straw e Bourdieu, mas também o estudo realizado em 2011 e 2012 (que consistiu em levantamento de matérias veiculadas na imprensa tradicional e alternativa nos últimos dois anos, a organização de entrevistas semiestruturadas com os atores, bem como de trabalho de campo executado em lugares estratégicos), busca-se avaliar neste trabalho: por um lado, se efetivamente nos últimos anos, vem se consolidando no Rio de Janeiro uma cena do jazz; e, por outro, se a "musicabilidade" e a "cultura das ruas" continuam promovendo grande mobilização social nesta cidade.

\section{Palavras-chave}

Comunicação. Cultura Urbana. Música. Jazz. Sociabilidade.

\section{Micael Herschmann I micaelmh@globo.com} Doutor em Comunicação pela Universidade Federal do Rio de Janeiro (UFRJ). Professor do Programa de Pós-Graduação em Comunicação da Universidade Federal do Rio de Janeiro (UFRJ).

\section{Cíntia Sanmartin Fernandes I cintia@ lagoadaconceicao.com}

Doutora em Sociologia Política pela Universidade Federal de Santa Catarina (UFSC). Professora do Programa de Pós-Graduação em Comunicação da Universidade do Estado do Rio de Janeiro (UERJ).

\section{Introdução}

Poder-se-ia dizer que o nicho de mercado do jazz (que engloba a música instrumental e 0 blues) ${ }^{1}$ teve um enorme crescimento no Rio de Janeiro (e no Brasil), em 2011 e 2012, e por conta disso, não só conseguiu alcançar visibilidade na mídia tradicional, mas também causou grande perplexidade entre os atores sociais que atuam direta e indiretamente nesta cena musical. Vários atores passaram a se perguntar as razões do atual aumento de interesse, isto é, em que medida 0 crescimento deste nicho atende uma demanda sociocultural por uma maior diversidade musical.

No levantamento realizado ${ }^{2}$ analisaram-se matérias jornalísticas veiculadas nos últimos anos pelas principais empresas de comunicação do país (especialmente as vinculadas às Organizações Globo e ao Grupo Folha), é foi possível atestar um crescimento expressivo do

Evidentemente, 0 jazz é um gênero musical com uma história específica, mas neste artigo ele é considerado como fazendo parte de um nicho de mercado que engloba também a música instrumental e o blues. Cabe destacar que: não só inúmeros atores sociais fazem esta associação, mas também que há uma relativa hegemonia de uma interpretação difusa do gênero (uma espécie de leitura free jazz) no Brasil. Vários produtores e artistas ressaltaram ainda que esta interpretação mais maleável do "gênero jazz" foi "estratégica", permitindo que o gênero ganhasse um pouco mais de solidez e sustentabilidade no mercado brasileiro (articulandose a outros ritmos e sonoridades).

Deixa-se aqui registrado os agradecimentos pelo apoio no desenvolvimento desta pesquisa: não só as assistentes de pesquisa Jaqueline Neves da Silva e Ana Clara Ribeiro Lages, mas também ao Conselho Nacional de Desenvolvimento Científico e Tecnológico (CNPq) e a Fundação de Amparo à Pesquisa do Estado do Rio de Janeiro (FAPERJ). 
jazz, inclusive no Rio de Janeiro: festivais como

Bourbon Street Fest, realizado no Parque Garota de Ipanema (que trouxe importantes bandas, tais como Orleans St. Jazz Band; Terrance Simien \& The Zydeco Experience; e Shamarr Allen \& The Underwags) e o Festival I Love Jazz, promovido ao lado do Centro Cultural Banco do Brasil, na Praça dos Correios do Centro (que trouxe artistas conhecidos, tais como Stacey Kent, Bucky Pizzarelli, Jack Wilkins e Judy Carmichael) "sacudiram" a cidade do Rio, em diferentes momentos, mobilizando um público inimaginável para eventos associados a este gênero (o público presente não era só 0 de consumidores tradicionais de jazz: composto por indivíduos de mais de 40 anos, de iniciados ou colecionadores, da classe A e B). ${ }^{3}$ Ainda que a maioria destes eventos aposte no glamour e status de se organizar concertos centrados na exibição de artistas estrangeiros, começa a aparecer gradativamente mais espaço para artistas locais nos eventos e, até mesmo, festivais dedicados a promover a cena local, como, por exemplo, o Festival Ouve.ai, realizado no Centro Cultural Oi Futuro Ipanema, da qual participaram bandas de músicos locais que estão despontando no mercado, tais como o Bondesom,
Quinteto Nuclear, Monte Alegre Jazz Hot Band e Nova Lapa Jazz (NLJ).

Além disso, dois eventos de grande sucesso - um temporário e outro regular - também chamaram a atenção do público e da crítica e que são indicativos importantes de um crescente interesse social. 0 primeiro foi 0 impacto gerado pela exposição Queremos Miles, organizada pelo Centro Cultural do Banco do Brasil do Rio de Janeiro e que mobilizou mais de 100 mil visitantes. ${ }^{4} \mathrm{E} 0$ segundo exemplo, são os concertos ao ar livre que - desde 2011 - vêm sendo realizados pelos jovens músicos do grupo Nova Lapa Jazz (que atualmente tocam no Largo Albino Pinheiro, ao lado da Praça Tiradentes) e que atraem regularmente cerca de duas mil pessoas, todas as $4^{\text {a }}$ feiras à noite. ${ }^{5}$ Se, por um lado, é possível perceber que ainda são poucas as gravadoras interessadas em lançar artistas nacionais; ${ }^{6}$ por outro lado, constata-se a emergência de um circuito carioca de casas de espetáculo (que estão abrindo cada vez mais espaço para 0 nicho do jazz), tais como: Studio RJ, Brasserie do Rosário, Clube Democráticos, Casa Rosa, Jazz na Taverna e Santo Scenarium.

Conferir artigos Bourbon Street Fest traz o jazz de Nova Orleans para SP e Rio (2010) e I Love Jazz, ambos publicados pelo Globo.

Exposição que reuniu material fotográfico e discográfico, bem como filmografia - especialmente documentários sobre a trajetória do mega ídolo de jazz Miles Davis. Cf. ESSINGER (2011).

Conferir as seguintes matérias jornalísticas: Helal Filho e Gomes (2011).

De fato encontramos alguns poucos artistas locais - de jazz, blues e instrumental - no catálogo de pequenas e médias gravadoras ou selos discográficos tais como Baratos Afins, Biscoito Fino, Bolacha Discos, Paradoxx, entre outros. 
Se for comparado o cenário atual com o passado recente, constata-se que estas mudanças no "nicho de mercado do jazz" são significativas. Na realidade, como observa o pesquisador e crítico Carlos Calado (2011), ${ }^{7}$ poder-se-ia argumentar (aumentando o escopo da análise proposta aqui) se não se estaria se estruturando um "circuito nacional do jazz" nos últimos anos:

Hoje já é possivel desfrutar shows de astros internacionais do jazz, do blues e de outros gêneros afins, durante quase todo 0 ano, em eventos programados em diversos locais do país. '0 Brasil se firmou como um mercado sólido e sério, nas últimas décadas', diz a produtora e cineasta Monique Gardenberg, que assina a direção artística da primeira edição do BMW Jazz Festival, em São Paulo e Rio. [...] Como a maioria dos festivais que têm usado a grife do jazz durante as últimas décadas, tanto no exterior quanto aqui, o BMW Festival também abre espaço para atrações de outros gêneros musicais como o blues [...]. Outro evento do gênero que estréia neste mês, com um formato diverso dos seus concorrentes, é 0 Illha de Toque Toque Jazz Festival, que oferece como atrativo extra o visual dessa praia da cidade de São Sebastião, no Litoral Norte paulista. [...] Uma característica comum a festivais de jazz e blues realizados nos últimos anos, em várias regiões do país, como os de Guaramiranga (CE), Garanhuns (PE), Ouro Preto (MG) ou Teresópolis (RJ), também norteia dois eventos programados para este mês: tanto o Rio das Ostras Jazz \& Blues Festival (RJ), como o Bourbon Festival Paraty (RJ) nasceram com 0 objetivo de contribuir para 0 incremento do turismo em suas localidades. [...] Edgard Radesca, produtor do Bourbon Festival Paraty, também ressalta a eficácia de seu evento em atrair turistas e diferentes públicos. [...] Qualquer semelhança com a linha musical do Bourbon Street Music Club que Radesca abriu com um grupo de amigos em 1993 em SP não é mera coincidência. A influência dessa cidade americana tão musical, conhecida mundialmente como berço do jazz, também orienta o Bourbon Street Fest, cuja nona edição está agendada para agosto, em São Paulo, Rio e Brasília. [...] Outra característica que aproxima festivais de jazz de diversas regiões do país, como os de Manaus (AM), Joinville (SC) ou Rio das 0stras (RJ), é a programação de atividades didáticas: geralmente, workshops e oficinas para estudantes de música, ministrados por artistas do elenco, além de palestras e debates. 0 Festival Choro Jazz Jericoacoara (CE), que vai realizar sua terceira edição [...] está se preparando para receber 40 estudantes de música da cidade norte-americana de Cazadero (Califórnia), interessados em participar de seus workshops. [...] "Os inconformados com a música de péssima qualidade executada nas rádios encontraram uma bela válvula de escape nos festivais de jazz que surgiram na última década, muitos com ingressos a preços acessiveis ou mesmo gratuitos", observa Maria Alice Martins, que produz desde 2001 o festival Tudo É Jazz, na cidade histórica de Ouro Preto (MG) (CALADO, 2011, p. 1).

Este autor vai mais longe: para ele estaria se formando um novo público consumidor de jazz no país:

Carlos Calado (2011, p. 1) sublinha as dificuldades que até bem pouco tempo os consumidores deste gênero enfrentavam para desfrutar do jazz aqui: "[...] quem já passou férias na Europa ou na América do Norte, especialmente durante os meses de verão, sabe que os festivais de jazz se destacam entre as atrações culturais oferecidas nesse período do ano. Realizados não apenas em metrópoles e grandes capitais, como Nova York, Montreal, Roma ou Viena, eventos desse gênero também levam a centenas de pequenas cidades europeias e americanas multidões de fãs atraídos por concertos ao ar livre, em praças e pontos turísticos, ou mesmo em auditórios e clubes de jazz. 0 Brasil já esteve mais distante de um cenário musical como esse. Ainda no início da década de 1990, quem quisesse apreciar ao vivo as últimas novidades jazzísticas tinha apenas duas opções: viajar para 0 exterior ou esperar pelo único evento anual do gênero naquela época, o Free Jazz Festival, que era realizado em São Paulo e no Rio". 
Esses festivais motivaram a formação de um público realmente jovem, que procura na internet dados sobre os músicos de jazz, baixa vídeos no YouTube e os compartilha no Facebook. Alguns se inspiram e vão estudar mais seriamente, para se tornarem músicos de jazz. Atualmente, em Minas Gerais, o jazz tem um público bem mais jovem que 0 do rock. [...] Um outro exemplo revelador [do crescimento do interesse e do circuito do gênero] é o Jazz na Fábrica, festival realizado durante o mês de maio pelo Sesc Pompeia, em São Paulo. Com um formato inovador, esse evento exibiu 23 atrações musicais: de conceituados jazzistas estrangeiros, como o saxofonista Archie Shepp, o trompetista Christian Scott e a cantora Dee Dee Bridgewater, até instrumentistas nacionais do primeiro time, como Toninho Horta, Arismar do Espírito Santo e a Orquestra Ouro Negro. Quem teve a sorte de acompanhar esses concertos, encontrou um público bem jovem, que aplaudia os improvisos dos músicos com uma euforia típica de torcedores de futebol. Um sinal de que outros festivais de jazz podem vir por aí (CALADO, 2011, p. 1).

Além disso, pode-se constatar na pesquisa realizada que, as reclamações dos artistas nacionais por mais espaço neste circuito nacional de festivais, entraves recorrentes para organizar este tipo de eventos e 0 crescimento deste nicho de mercado motivaram os coordenadores de oito festivais a criarem, em 2011, a Associação Brasileira dos Produtores de Festivais de Música Instrumental, Jazz e Blues (ABRAFEST) ${ }^{8}$ Entre os primeiros projetos musicais da entidade destaca-se o Palco Abrafest que estabeleceu a obrigatoriedade deste espaço dedicado aos "novos talentos nacionais" em todos os festivais organizados pelos associados. Busca-se com esta medida ampliar a identificação entre artistas e público, sensibilizando especialmente os consumidores mais jovens.

Tendo em vista o quadro apresentado, poderse-ia indagar: estamos diante da emergência de uma nova cena do jazz no Rio de Janeiro (e mesmo no Brasil) e/ou de casos isolados de grande êxito (e, talvez, resultado de um modismo passageiro), como, por exemplo, no caso da banda Nova Lapa Jazz ou dos festivais realizados nas ruas ou em ambientes fechados? Em que medida o interesse pelo jazz é relativo, ou seja, na realidade evidencia apenas uma receptividade do público em relação aos concertos realizados nos espaços públicos? Isto é, será que não indicaria também uma significativa demanda social por programas acessíveis e baratos? E, finalmente, 0 interesse pelos eventos musicais realizados nas ruas e praças não colocaria em evidência um forte desejo de "estar junto" e/ou a enorme relevância da "cultura musical das ruas", especialmente no Rio de Janeiro? Este artigo se propõe a refletir sobre estes questionamentos.

São membros fundadores da ABRAFEST os seguintes festivais (e seus respectivos organizadores): Bourbon Street Fest de São Paulo, Bourbon Street Fest de Paraty, Fest Bossa \& Jazz de Natal, Festival Blues nos Pirineus, Festival de Jazz e Blues de Guaramiranga, Festival República Blues de Brasília, Rio das Ostras Jazz \& Blues Festival, Phoenix Jazz Festival da Praia do Forte e, finalmente, Festival Vijazz e Blues de Viçosa. 


\section{Entraves para 0 desenvolvimento de uma cena do jazz}

Alguns mais pessimistas afirmam que o público no

Brasil é apenas receptivo ao jazz tocado ao "estilo dixieland", mais performático (dançante) e mais estruturado no formato de canção. Analisando a história do jazz no Brasil (LABRES; SANTOS, 2011; NAPOLITANO, 2002; MUGGIATI, 1999; CALADO, 2007; MCAAN, 2010; TINHORÃO, 1991; HOBSBAWN, 2009; CABRAL, 1997; BASTOS, 2005; SCARABELOT, 2012), é possível constatar que, apesar da pouca visibilidade (ou do episódico destaque alcançado na mídia) e do mercado limitado (tendência do jazz em manter-se como alvo de consumo de um público elitizado), este estilo musical sempre dialogou com os chamados "gêneros musicais nacionais", estabelecendo uma relação bastante profícua e criativa. Poderse-ia oferecer os exemplos das chamadas jazz- bands, na primeira metade do século XX; ou da bossa nova, na segunda metade do mesmo período (SOUZA et al., 1988; CALADO, 2007; SCARABELOT, 2012). ${ }^{9}$

As duas perguntas capitais que orientaram as entrevistas semiestruturadas que foram realizadas com os atores no início de 2012 era a seguinte: ${ }^{10}$ Efetivamente, existe uma cena do jazz (tocado por artistas brasileiros) no Rio de Janeiro ou mesmo no Brasil? Há condições para o florescimento deste nicho de mercado hoje?

A esta altura, vale a pena ressaltar que 0 conceito de "cena" (STRAW, 2006) foi empregado como uma relevante "ferramenta interpretativa" para caracterização das expressões culturais contemporâneas, marcadas por um estilo próprio e com visibilidade social. Esta noção foi utilizada aqui como uma alternativa ao conceito

Tomando como base os laços sólidos construídos pela bossa nova com o jazz, poder-se-ia dizer que o penúltimo ciclo de mais visibilidade do jazz (antes do contexto atual) ocorreu entre os anos de 1970 e de 1980.0 início deste ciclo começou no final da década de 1970, com o Festival Internacional de Jazz de São Paulo e o Free Jazz Festival, os quais pavimentaram o caminho dos diversos eventos que os sucederam: não só por ter reunido, em suas edições, astros de primeira grandeza do jazz e da música instrumental brasileira e internacional, mas também porque os concertos foram transmitidos para o resto do país pela televisão (principal meio de comunicação de massa na época). Por terem um custo menor que os festivais de pop rock, alguns produtores culturais passaram a se dedicar nas décadas seguintes a realizar eventos do gênero, tais como Heineken Concerts, Chivas Jazz Festival e Bridgestone Music (CALLADO, 2007; SCARABELOT, 2012).

Construindo um diálogo com os resultados das pesquisas sobre cenas e circuitos apresentadas na coletânea Nas bordas e fora do mainstream musical (HERSCHMANN, 2011) neste artigo foi empregado como metodologia de pesquisa: a) levantamento de matérias jornalísticas nos dois últimos anos nos principais jornais do país; b) extenso trabalho de campo realizado em casas de espetáculo e espaços públicos da cidade do Rio de Janeiro; c) e entrevistas semiestruturadas com sete atores (estratégicos da suposta cena carioca): Thiago Vedová (produtor do Festival Ouve.al), luri Nicolsky e Gabriel Ballesté (músicos do Nova Lapa Jazz), Marco Serragrande (músico do Monte Alegre Jazz Hot Band), Pedro Mangia e Matias Zibecchi (músicos do Bondesom) e, finalmente, Thiago Spósito (produtor do Santo Scenarium e Brasserie do Rosário). Além disso, sublinha-se que se tomou com principal referência teórico-metodológica, para 0 as reflexões aqui desenvolvidas, o trabalho seminal (especialmente a pesquisa de campo) que Keith Negus realizou com o nicho de mercado do hip-hop nos EUA e os estudos de gêneros musicais que este autor organizou junto a importantes gravadoras (mais detalhes, cf. NEGUS, 2005). Cabe destacar ainda que os resultados apresentados neste artigo foram obtidos ao longo da pesquisa sobre circuitos e cenas musicais (intitulada "Indústria da Música do Estado do Rio de Janeiro", a qual vem sendo desenvolvida desde 2009, com o apoio do CNPq e da FAPERJ) e que está centrada especialmente sobre a produção, distribuição e consumo de música ao vivo no Rio de Janeiro. 
de "subcultura", o qual não se adéqua bem as dinâmicas sociais que estão relacionadas às práticas culturais contemporâneas (na medida em que estas tendem a serem mutáveis, fugazes, fluidas e, muitas vezes, arbitrárias). ${ }^{11}$

Para Straw (2006), a cena sugere mais do que a fluidez agitada da sociabilidade urbana: compele-nos a examinar o papel das afinidades e interconexões que marcam e regularizam os itinerários espaciais de pessoas, coisas e ideias, através do tempo. A noção de cena problematiza as redes, afiliações e circuitos das práticas culturais dos espaços urbanos contemporâneos, permitindo uma abordagem mais ampla que envolve contextos - histórico, social e econômico -, bem como estratégias estéticas e ideológicas (FREIRE FILHO; FERNANDES, 2005). Poder-se-ia dizer que se trata de espaços de criação e consumo cultural relacionados a temáticas específicas, envolvem ações estratégicas e, muitas vezes, a construção de iniciativas intencionalmente "alternativas" (aos nichos de mercados do mainstream). Portanto, é um conceito que permite compreender as várias forças presentes em um contexto específico, relacionando os atores e o seu entorno (STRAW, 2006).

Trabalhando com os conceitos de "campo", de "distinção" e "habitus" de Bourdieu (1983, 2007), Garson argumenta que, em geral, ignora-se que a elaboração de uma "cena musical" é o resultado não só da criatividade dos atores, mas também de uma construção social, isto é, "[...] depende de toda uma rede de relações sociais compostas por agentes (músicos, bandas, empresários, jornalistas, donos de casa noturna) e instituições (gravadoras, veículos de comunicação, lojas de disco) que lhes oferecem suporte" (GARSON, 2009, p. 6). Além disso, o autor sublinha que 0 reconhecimento de todo tipo de nova sonoridade é sempre imerso em um processo de lutas, visto que as forças que alicerçam as cenas musicais, em um determinado momento da trajetória das mesmas, são obrigadas a se reorganizarem no sentido de comportar as dinâmicas das inovações emergentes. Portanto, buscando ressaltar os aspectos "reprodutivos" (estruturantes) da cena (geralmente mais notória por sua fluidez), Garson destaca os aspectos conservadores que estabilizam a cena (inclusive como nicho de mercado), legitimando o lucro simbólico e material obtido pelos atores envolvidos direta e indiretamente com algum gênero musical e grupos sociais (GARSON, 2009, p. 6).

A questão central, portanto, é a seguinte: no contexto analisado, há condições para a construção de um habitus (BOURDIEU, 2007) em torno do jazz? Como destaca o produtor cultural Vedová:

[...] a presença de programas de rádio, blogosfera e redes sociais dando visibilidade as iniciativas; realização de concertos na rua e em casas de espetáculo; espaço significativo 
e freqüente na mídia tradicional; presença de uma produção fonográfica local regular; e a estruturação de circuito de festivais, são todos vetores fundamentais para 0 desenvolvimento hoje de uma cena musical qualquer. ${ }^{12}$

Vedová reconhece que os atores no nicho do jazz no Brasil contam apenas com as redes sociais, concertos pontuais realizados na rua, alguns organizados em festivais e, poucos, executados em casas de espetáculo. Ele não identifica propriamente uma cena organizada e próspera, mas ressalta que há mais condições hoje para que esta cena deslanche no Rio de Janeiro e no restante do país, sobretudo se houver um diálogo mais fortalecido entre as bandas (e, se possível, também com os produtores). Entre os aspectos destacados por ele, que podem ser o fiel da balança neste processo, sublinha 0 fato de que hoje os grandes festivais do país (especialmente aqueles vinculados a ABRAFEST) estão mais preocupados atualmente em incluir artistas brasileiros em seus eventos.

A partir deste ano a Abrafest vai colocar as novas bandas locais em todos os festivais. Esta associação quer utilizar a nova cena local para ampliar o mercado, atingir um público mais jovem. [...] está abrindo espaço para bandas como a Bondesom e 0 Paraphernalia porque querem ganhar mais dinheiro [...] pagando menos aos brasilei- ros do que aos estrangeiros. Acho que 0 NLJ, o Quinteto Nuclear e outras bandas de jazz podem se aproveitar da estratégia de participar de eventos de rua. Contudo, nem sempre o público vai pelo jazz ao evento, mas sim pelo programa. De qualquer modo, é uma forma do segmento do jazz ganhar a atenção das pessoas, ou seja, de formar um público consumidor. São estas bandas novas e locais que produzem o som que é capaz de atrair os mais jovens. Os empresários estão começando a se dar conta disso. Acho que a cena carioca e brasileira está se estruturando [...]. Eu acho que no Rio de Janeiro as bandas de jazz e instrumental estão num momento em que elas estão colhendo frutos, mas lamentavelmente não estão dialogando mais entre si ou mesmo com os produtores. ${ }^{13}$

Este produtor cultural identifica, nesta mudança de tendência de organização dos festivais, uma tentativa de superar limitações recorrentes do mercado nacional, isto é, um esforço de produzir maior identificação de um público - mais jovem e menos elitizado - com os músicos e bandas locais, especialmente aqueles que estão emergindo no mercado, nos últimos anos. Conforme assinala Vedová, até bem pouco tempo havia uma percepção equivocada de que 0 jazz se constituiu em uma expressão musical, em geral, para ser contemplada e executada "[...] em clubes de whisky, destinada a um público mais velho, que fica sentado, bebendo e desfrutando aquela virtuose solitária do 
músico." As novas bandas vêm desconstruindo este imaginário social. ${ }^{14}$

Ainda que seja difícil isolar estes vetores condicionantes e explicativos do êxito do jazz, a esta altura poder-se-ia indagar: no caso do Rio de Janeiro, o "capital simbólico" (BOURDIEU, 2007) que vem sendo acumulado pelo jazz, está alicerçado mais no que exatamente? Ou melhor, qual é o peso da dinâmica da "cultura das ruas" e da cena musical propriamente dita, neste processo em curso?

\section{Balanço do sucesso do grupo Nova Lapa Jazz: a força da experiência musical na rua}

A capacidade de mobilização das experiências musicais presenciais e das interações realizadas em certos "ambientes" (que integram de forma harmoniosa vetores como sonoridade e espacialidade) vem chamando a atenção de importantes atores e lideranças da cidade do Rio. Eventos de jazz vêm ganhando visibilidade no cotidiano, especialmente os realizados no Centro da cidade - que articulam, por exemplo, uma experiência sonora à arquitetura colonial e histórica desta localidade - e estão se tornando cada vez mais recorrentes..$^{15}$ Essas "musicabilidades" (sociabilidades que gravitam em torno da música) ou "sociabilidades sônicasmusicais" (FERNANDES, 2011) florescem com frequência no Rio e são resultado de insurgências das ruas, do engajamento e da atuação dos atores sociais no espaço público. Pode-se dizer que a experiência musical promovida pelo grupo Nova Lapa Jazz (NLJ) vem "amalgamando relações sociais" ${ }^{\prime 16}$ e vem permitindo construir processos de "reterritorialização" (DELEUZE, GUATTARI, 1995) significativos nesta microrregião.

A banda do NLJ, formada no início de 2011 (a partir das Jam Sessions abertas todas as quartas-feiras "aos amigos", na Rua da Lapa

Segundo Vedová: “[...] no Rio de Janeiro a gente está nitidamente vendo um movimento em que a força do blues, do instrumental e do jazz vem cada vez mais se evidenciando [...]. Ao mesmo tempo, é preciso relativizar é perceber que o jazz está emergindo como componente de um evento noturno, que azeita o encontro de jovens, isto é, o encontro de pessoas. A música não é necessariamente o componente principal da festa. Acho que o público que vai assistir ao Nova Lapa Jazz não está querendo necessariamente ver esta banda [...]. Acredito que as pessoas que vão ali vão atrás de um evento diferente de um evento de boate, de casas de espetáculo [...] Não acho que duas mil pessoas estão indo ao evento do NLJ para ver o show, acho que vão pela paquera, pelo programa com a galera. 0 público carioca é meio preguiçoso para correr atrás de novas bandas, mas gosta da rua e preponderantemente busca isso".

Cabe ressaltar que as rodas de choro e samba, realizadas nas ruas, vêm também mobilizando de forma expressiva os atores sociais no centro histórico da cidade do Rio de Janeiro (mais detalhes, cf. FERNANDES, 2011).

Parte-se do pressuposto de que as interações afetivas e sociabilidades das cenas musicais constroem, em alguma medida, um tipo de "elo", isto é, como sugere Maffesoli (1995), erigem um novo ethos compreendido como uma "ética da estética". Este sociólogo do cotidiano retoma e agencia Heidegger, cunhando a noção de "ética da estética" (aisthesis como a base para a construção de uma "socialidade" ou um "estar junto" na atualidade): identifica a emergência de um novo ethos, o qual pode ser constatado nas novas formas e manifestações de solidariedade emocionais e afetivas que se fazem cada vez mais presentes hoje (MAFFESOLI, 1995, p. 48-49). 
em frente ao bar Nova Lapa), após dois meses, passou a ter um perfil mais claro e a atrair nos seus concertos um público superior a quinhentas pessoas. ${ }^{17}$ No entanto, conforme um dos músicos destaca, essa mudança passou a gerar reclamações da vizinhança e trouxe (consequentemente) muitos problemas tanto para o bar como para a banda. Embora tivessem re-territorializado e revitalizado o lugar, o poder público não reconheceu de imediato o direito de permanecerem na Rua da Lapa: na ocasião foi aplicado o chamado "choque de ordem" (conjunto de medidas repressivas que visam garantir o zelo pelas normativas municipais), o qual obrigou músicos e público a se retirarem daquele local. No entanto, apesar da ação da Prefeitura do Rio, as negociações prosseguiram e 0 resultado para os músicos foi surpreendente favorável, pois além de conquistarem a permissão para tocar na rua, conseguiram um espaço no centro histórico com uma infraestrutura mais adequada para atender um público crescente. ${ }^{18}$
Hoje, tocando no Largo Albino Pinheiro circundado pelo Instituto de Filosofia e Ciências Sociais, Real Gabinete Português, Teatro João Caetano e o Centro Cultural Carioca - e com um repertório que mistura músicas dos clássicos do jazz como Coltrane, Davis e Pascoal (entremeado com a execução de músicas autorais), a banda conquistou um público significativo, erigido a partir da experiência da rua e mantida (e até ampliada) para e pelas redes sociais. Utilizando algumas plataformas de grande popularidade da web (tais como o facebook e myspace), o grupo conseguiu angariar mais de 13 mil seguidores, alguns deles muito ativos. Essa excelente participação e relação com o público no contexto on-line e off-line permitirá que a banda lance um CD em breve, viabilizado através de crowdfunding (organizado através do coletivo Catarse).

No trabalho de campo executado foi possível atestar que o público que acompanha o NLJ é bastante heterogêneo. Para Nicolsky (saxofonista e líder da banda), essa heterogeneidade é rica e desafiadora, pois reúne gente de todas as

Entrevista do músico Gabriel Ballesté, concedida aos autores no dia 25 de janeiro de 2012.

Conforme Ballesté recorda: "[...] estávamos buscando uma solução e o subsecretario do Centro Histórico do Rio sugeriu nos deslocássemos para frente do Gabinete Português de Leitura. Cogitávamos a Cinelândia (que nos parecia sempre muito agitada) e 0 centro da Praça Tiradentes...que nos parecia grande demais!. [...] 0 subsecretário nos ofereceu uma autorização para atuar neste espaço maravilhoso, de muita tradição, perto do IFCS, do Gabinete Português e do Teatro João Caetano. Eles ofereceram mais do que isso para gente: tudo que tinham a disposição foi cedido. Eles apoiaram mesmo e seguem nos apoiando. Eles disponibilizam palco, disponibilizam banheiro químico e destacaram policiais para fazer a ronda e dar mais segurança ao público durante 0 show. Além do poder público, o Centro Cultural Carioca (CCC) também nos apóia disponibilizando o som e energia elétrica. Com a parceria do CCC e do poder público conseguimos arcar com este evento semanal”. Parte-se do pressuposto de que as interações afetivas e sociabilidades das cenas musicais constroem, em alguma medida, um tipo de "elo", isto é, como sugere Maffesoli (1995), erigem um novo ethos compreendido como uma "ética da estética". Este sociólogo do cotidiano retoma e agencia Heidegger, cunhando a noção de "ética da estética" (aisthesis como a base para a construção de uma "socialidade" ou um "estar junto" na atualidade): identifica a emergência de um novo ethos, o qual pode ser constatado nas novas formas e manifestações de solidariedade emocionais e afetivas que se fazem cada vez mais presentes hoje (MAFFESOLI, 1995, p. 48-49). 
classes sociais para ouvir música instrumental e desfrutar de um espaço público da cidade. ${ }^{19} \mathrm{Ou}$ seja, manifesta-se nessa experiência sonora uma significativa troca entre diversos grupos sociais da cidade, os quais se reúnem neste espaço semanalmente. Evidentemente, os músicos estão conscientes de que nem todo mundo que se desloca para este evento é conhecedor e amante de jazz.

Tocar na rua é genial! Na verdade, a nossa relação com o público é baseada no compromisso de estar aqui, de tocar toda quarta, entendeu? As pessoas acolheram esse evento, não só aqueles que conhecem o jazz, mas também o público que não conhece 0 gênero. Isso tem um significado especial para gente: você ver que pessoas que não conheciam aquele estilo, não sabiam mesmo [...]. Vinham mais com o objetivo de beber, ver os amigos e paquerar. De repente começam a gostar e estão ali vivenciando esta experiência musical de forma plena. Alguns foram se informar e hoje entendem um pouco mais de jazz. É muito bacana a troca com o público, constatar o carinho e crescente interesse de todos. [...] A nossa relação com o público é ótima e conseguimos reunir nos eventos de rua uma média de 2 mil pessoas semanalmente. ${ }^{20}$

Ratificando o discurso dos membros da banda, nos relatos colhidos junto aos freqüentadores, muitos afirmam que o estilo musical, a princípio, não era a principal motivação de estar ali. Inclusive, uma das frequentadoras entrevistadas acredita que, para além dos músicos tocarem muito bem, o show desta banda jazz tem atraído muita gente porque é oferecido de forma gratuita. ${ }^{21}$

Outro aspecto interessante diz respeito à relevância da espacialidade. Ao ser indagada sobre a mudança de lugar (da Rua da Lapa para o Largo), esta consumidora argumenta que o espaço atual é melhor porque, além de permitir acomodar - com mais segurança - todo o público, todos conseguem ouvir o som, o que era impossível anteriormente na antiga localidade. ${ }^{22}$ Esta frequentadora identifica nesta mudança de lugar, uma ampliação das possibilidades das condições do público apreciar artisticamente este evento:

[...] Lá era meio ruim, sabe? E o som nem estava tão bem amplificado. E o público ia mais

Nicolsky, líder da banda, assinala que "[...] tem gente de todos os segmentos sociais, de todas as partes do Rio de Janeiro [...] 0 bacana do Centro é que é um lugar de encontro, de passagem [...] a idéia é oferecer um evento barato, de rua, para um pessoal que vem a pé, de ônibus e metrô". (Entrevista do músico luri Nicolsky, concedida aos autores, no dia 25 de janeiro de 2012).

Entrevista do músico Gabriel Ballesté, concedida aos autores, no dia 25 de janeiro de 2012.

Para a consumidora entrevistada "[...] estão fazendo sucesso porque tocam de graça e as pessoas podem vir toda quarta aqui, ou seja, o programa é sair do trabalho ou da faculdade e vir para o jazz [...]" (Entrevista da frequentadora Catarina Branco, concedida aos autores, no dia 27 de janeiro de 2012).

Segundo a frequentadora Catarina Branco, "[...] o espaço anterior era muito pequeno era um estacionamento que fica apertado com tanta gente que aparecia ali. Tinha quartas que juntava cerca de umas 600 pessoas, mas as condições eram muito precárias [...] toda aquela festa ia acabar em confusão a qualquer momento". 
pelo programa, pela galera mesmo, não era nem pelo som, porque o som rolava, de fato, dentro do bar. Para escutar o som você tinha que ficar grudado na grade do prédio Agora, aqui no Largo, o pessoal vem pela música. Acho que naquela época muita gente não ia pela música [...]. Ou seja, estão gostando da música hoje por ter se ampliado o espaço, entendeu? É bacana perceber que muita gente hoje em dia vem pela música mesmo. Às vezes a banda começa a tocar determinada música e o pessoal reconhece 0 som, fica animado e começa inclusive a dançar. ${ }^{23}$

Assim, parte-se do pressuposto neste trabalho de que a "cultura da rua" é um importante vetor, o qual explicaria em boa medida o êxito do NLJ (e também dos blocos de carnaval, das rodas de samba e de choro) no cotidiano desta urbe. Reiterando esta tese, Nicolsky afirma que "[...] a proposta de ir tocar nos espaços públicos foi inspirada na forte presença da cultura de rua, que existe no Rio. 0 processo de ocupação da rua foi meio espontâneo, mas também notamos logo que havia um potencial nesta iniciativa. Por isso abraçamos esta ideia, como uma estratégia do grupo e deu certo [...]" ${ }^{24}$ Em outras palavras, este encontro, que deveria ser uma festa despretensiosa para os músicos foi convertido, de certa maneira, num relevante evento gratuito que integra a agenda oficiosa da cidade.

0 discurso de outro freqüentador assíduo auxilia a dimensionar a importância da ocupação das áreas públicas da cidade. Sua narrativa ressalta a força de uma experiência musical capaz de conquistar um público carioca que ainda vê o jazz com certo preconceito. Em outras palavras, este consumidor sugere que o público em geral encara o jazz como um estilo refinado, contudo ele nota que estas pessoas estão dispostas a participar do show na rua por se constituir em um lugar do encontro, um espaço para a realização de interações afetivas: "[...] não sou fã de jazz, mas apareço com frequência porque a galera e os amigos costumam estar pela área. Confesso que não pagaria para ver um show de jazz numa casa de espetáculo. 0 mais importante no evento do NLJ é que acontece na rua e de graça. Do contrário, iria limitar muito o público, certamente iria dar uma elitizada".

Tendo em vista os relatos apresentados, poder-se-ia afirmar que a "cultura de rua" vem desempenhando um papel importante

Entrevista da frequentadora Catarina Branco, concedida aos autores, no dia 27 de janeiro de 2012.

Esta estratégia possibilitou, conforme argumenta Nicolsky, tornar mais sedutor - num primeiro momento (para um público ainda neófito) - 0 trabalho de uma banda que atua sem vocal e que realiza muitas improvisações e solos complicados em cada música: "[...] este é um tipo de som só era executado em casas fechadas [...] e, digamos, mais elitizadas, ou seja, dirigidas a um público mais restrito [...], portanto, a intenção de ir para a rua, desde o início, era mostrar que 0 jazz poderia ser um som curtido na noite, por um público mais amplo [...]. Acho que este foi o nosso maior feito: mostrar aos outros grupos de jazz que a ocupação das ruas pode ser um caminho para conquistar o público" (Entrevista do músico luri Nicolsky, concedida aos autores no dia 25 de janeiro de 2012).

Entrevista do frequentador Nicolas Maués M. Monte, concedida aos autores, no dia 27 de janeiro de 2012. 
na emergência hoje do jazz na cidade do Rio

de Janeiro. Reiterando esta interpretação,

Serragrande, líder do "Monte Alegre Hot Jazz

Band", faz o seguinte comentário:

Viajei muito pelo país e noto que a cultura do Rio é diferenciada [...]. Talvez a cultura de rua que mais se aproxime seja a de Salvador [...]. Apesar da violência e das condições adversas, o carioca gosta de estar na rua: de beber na rua, de encontrar os amigos na esquina. Desde criança o pai leva o sujeito na roda de samba e os cariocas estão habituados com isso, estão familiarizados. Acho que esse aumento de interesse pelo jazz foi só mais uma sacação. Ou seja, é mais uma expressão musical que acontece nas ruas do Rio. Por isso pode-se dizer que a cultura de rua do Rio de Janeiro é diferenciada, talvez única no Brasil. ${ }^{26}$

Assim, pode-se afirmar que essa "cultura

de rua" carioca vem fundando relevantes territorialidades. ${ }^{27}$ Mais do que isso: a hipótese central aqui analisada é a de que há "territorialidades sônicas-musicais" significativas sendo construídas no cotidiano do Rio de Janeiro e que a análise das mesmas permite compreender a trama urbana de uma perspectiva menos usual, isto é, possibilita construir uma "cartografia sensível" da cidade, que na maioria das vezes, não coincide com o mapeamento frequentemente realizado pelos tecnocratas do poder público. ${ }^{28}$

\section{Considerações finais}

Tendo em vista as entrevistas (e observações de campo) realizadas, poder-se-ia destacar que a maioria dos atores acredita que há uma cena de jazz "em construção" no Rio de Janeiro e no país hoje. ${ }^{29}$ Sustentam esse argumento, sugerindo a emergência de uma nova cartografia composta por: casas noturnas, festivais, redes sociais e espaços públicos. Aliás, a ocupação de espaços públicos foi destacada, pela maioria dos atores,

Entrevista do músico Marco Serragrande, concedida aos autores, no dia 15 de janeiro de 2012.

Estas territorialidades colocam em primeiro plano a ritualização da vida cotidiana: para Maffesoli $(2001$, p. 86) "[...] é aí que convém buscar o fundamento do apego afetivo ou passional que liga o indivíduo ou o grupo a qualquer que seja 0 território". Essa espacialidade, que abriga o NLJ, desenha um corpo que possui uma forma (SIMMEL, 2006), evidencia-se em um estilo (de vida e musical) e territorialidade. A cidade, portanto, é constituída no dia a dia por essas tramas que ganham contornos e formas a partir de suas sociabilidades, de existências cotidianas, nas quais circulam os imaginários enunciados por aqueles que a vivem e compartilham experiências.

Além disso, neste ensaio, parte-se da premissa que "ocupar as ruas" com a "musicabilidade" não só permite resignificar e transmutar o sentimento de insegurança vivenciado no cotidiano de várias metrópoles brasileiras, mas também colocar em evidência uma demanda (e direito) social de acesso ao lazer e, quiçá, a esta cidade (FERNANDES, 2011).

Reforçando os discursos anteriormente apresentados e com uma perspectiva bastante otimista em relação à existência de uma cena na cidade, Nicolsky (líder do NLJ) argumenta que a cena do Rio de Janeiro está constituída e totalmente aquecida: "[...] Já há alguns anos que Minas Gerais e São Paulo têm uma cena de jazz dirigida a um público mais jovem. No Rio estourou em 2011. Antes, no Rio, o público era mais seleto, a grande maioria de indivíduos ricos, pessoas de mais idade [...]. Hoje temos uma cena do jazz aquecida no Rio de Janeiro, pois ao mesmo tempo em que a gente estava fazendo jazz na rua, aconteceram festivais como 0 Bourbon, o 'I Love Jazz' e outros eventos de jazz na cidade. Isso tudo trouxe uma visibilidade para a cena local. Agora você percebe que se tem evento de jazz acontecendo na cidade, esses são em geral bem aceitos e mobilizam um grande público" (entrevista do músico luri Nicolsky, concedido aos autores, no dia 25 de janeiro de 2012). 
como sendo uma estratégia de grande relevância para a formação da cena, especialmente devido ao fato de que permite atingir um novo segmento de público (mais jovem), não habituado a consumir este gênero musical.

Acho que está emergindo uma cena de jazz e o sucesso do NLJ é bom para todos [...]. Tudo que está acontecendo é maravilhoso! Enquanto a música tá por aí, tá tocando, tá tudo certo. [...] A galera do NLJ está dando continuidade ao que já vinha sendo feito por outros grupos, tais como o Bondesom, Paraphernália, Quinteto Nuclear e o grupo do André Vasconcelos [...] a gente tá tocando em casas lotadas há mais de um ano e meio, como na Casa Rosa, Santo Scenarium e Jazz na Taverna [...] isso é uma coisa que vêm acontecendo há mais tempo, $\mathrm{e}$ que agora apenas se consolidou com um apoio maior da imprensa. [...] 0 NLJ e a capacidade que um evento de rua tem em mobilizar 0 público também ajudaram [...]. Estamos todos preocupados em ajudar a popularizar mais 0 jazz [...] assim, o nosso show não pode custar mais do que 20 reais. ${ }^{30}$

Spósito, produtor de duas importantes casas noturnas do Centro do Rio (do Santo Scenarium e da Brasserie do Rosário) argumenta que estaria ocorrendo a emergência de uma cena, "[...] mas com características distintas da cena da década de 1980, pois hoje há espaço para uma casa de música instrumental no coração da Lapa, território historicamente consagrado do samba". Ainda segundo ele: "[...] até bem pouco tempo, o jazz tinha o rótulo de ser música chata [...]. Tanto que as pessoas diziam para não botar jazz e pediam para colocar samba, chorinho ou bossa nova. Hoje mudou, o público vem por causa deste gênero musical. Estas casas [nas quais trabalha como produtor] compraram a briga de se apresentarem como espaços privilegiados do jazz. ${ }^{31}$

Como se pode constatar, pelos argumentos e informações apresentados, há um movimento intenso dos produtores e músicos do nicho do mercado do jazz que vem criando melhores condições para que uma cena local (talvez nacional) floresça nos próximos anos. Em outras palavras, pode se atestar na pesquisa organizada que a produção e consumo do jazz vêm se capilarizando pela cidade, seja em eventos públicos (em concertos de rua, festivais ou shows em quiosques da orla na Zona Sul da cidade) ou nos espaços privados (especialmente das casas noturnas), mobilizando assim, crescentemente, os profissionais das mídias tradicionais e os usuários redes sociais.

Em suma, é inegável que esse movimento rizomático vem potencializando a possibilidade da edificação de um novo conjunto de habitus que passa a gravitar entorno do jazz. Ao mesmo tempo, pode-se verificar também, ao longo deste trabalho, que a tradicional experiência musical nas ruas do Rio de Janeiro - não necessariamente associada exclusivamente ao universo do jazz (como já foi mencionado anteriormente, as rodas de samba 
e choro tradicionalmente sempre ocuparam com êxito os espaços públicos desta urbe) - revestese de uma relevância sociopolítica, contribuindo de forma significativa para a construção de um ethos (MAFFESOLI, 2001), quiçá de um cotidiano um pouco menos excludente nesta megalópole contemporânea.

\section{Referências}

BASTOS, Rafael José de Menezes. Les Batutas, 1922: uma antropologia da noite parisiense. Revista

Brasileira de Ciências Sociais, São Paulo, v. 20, n. 5, p.177-196, 2005.

BENNETT, Andy. Subcultures or neo-tribes? Rethinking the relationship between youth, style and musical taste. Sociology, v. 3, n. 3, p. 599-617, 1999.

BOURBON Street Fest traz o jazz de Nova Orleans para SP e Rio. G1. Pop \& Arte, 2011. Disponível em: < http://g1.globo.com/pop-arte/noticia/2010/08/ bourbon-street-fest-traz-0-jazz-de-nova-orleans-parasp-e-rio.html> . Acesso em: 06 fev. 2012.

BOURDIEU, Pierre. A distinção: Crítica Social do Julgamento. São Paulo: Zouk, 2007.

. 0 campo científico. In: ORTIZ, Renato (Org.).

Pierre Bourdieu - Sociologia. São Paulo: Ática, 1983. p. 122-155.

CABRAL, Sérgio. Pixinguinha, vida e obra. Rio de Janeiro: Editora Lumiar, 1997.

CALAD0, Carlos. 0 espetáculo do jazz. São Paulo: Perspectiva, 2007.

Circuito Nacional dos Festivais de Jazz no

Brasil. Valor Econômico, São Paulo, 03 jun. 2011.

Caderno Eu \& Fim de Semana, p. 1.

DELEUZE, Gilles; GUATTARI, Felix. Mil platôs. São Paulo: Ed. 34, 1995.
ESSINGER, Silvio. Trajetória do jazzista Miles Davis essencial é revista em passeio longo, mas compensador. o Globo. 2011. Disponível em: http://oglobo.globo.com/ cultura/trajetoria-do-jazzista-miles-davis-essencialrevista-em-passeio-longo-mas-compensador-2690902. Acesso em: 20 jan. 2012.

FERNANDES, Cíntia S. Música e sociabilidade: 0 samba e choro nas ruas-galerias do centro do Rio de Janeiro. In: HERSCHMANN, Micael (Org.) Nas bordas e fora do mainstream: novas tendências da música independente no início do século XXI. São Paulo: Editora Estação das Letras e das Cores, 2011.

FREIRE FILHO, João. Reinvenções da resistência juvenil: os estudos culturais e as micropolíticas do cotidiano. Rio de Janeiro: Mauad X, 2007.

; FERNANDES, Fernanda Marques. Jovens, espaço urbano e identidades: reflexões sobre 0 conceito de cena musical. In: CONGRESSO BRASILEIRO DE CIÊNCIAS DA COMUNICAÇÃO, 28., 2005. Rio de Janeiro. Anais... Rio de Janeiroba: INTERCOM, 2005.

GARSON, Marcelo. Bourdieu e as cenas musicais. In: CONGRESSO BRASILEIRO DE CIÊNCIAS DA COMUNICAÇÃO, 32., 2009. Curitiba. Anais... Curitiba: INTERCOM, 2009. Disponível em: < http://www. intercom.org.br/papers/nacionais/2009/resumos/R43260-1.pdf > . Acesso em: 05 fev. 2012.

GOMES, Rodrigo. Ensaio de quinteto de jazz formado por estudantes de Música da UNIRIO vira ponto de encontro semanal, de graça e ao ar livre. 0 Globo. Rio de Janeiro, 06 jul. 2011. Caderno Magazine, p. 12.

HELAL FILHO, William. 0 som da rua no palco. 0 Globo. Rio de Janeiro, 29 ago. 2011. Caderno Magazine, p. 4-5.

HERSCHMANN, Micael (Org.) Nas bordas e fora do mainstream. São Paulo: Editora Estação das Letras e das Cores, 2011.

A Indústria da música em transição. São Paulo: Editora Estação das Letras e das Cores, 2011. 
HOBSBAWN, Eric. A história social do Jazz. Rio de Janeiro: Paz e Terra, 2009.

I LOVE Jazz. 0 Globo. Rio Show, 2011. Disponível em: $<$ http://rioshow.oglobo.globo.com/musica/eventos/ilove-jazz-2865.aspx> . Acesso em: 03 fev. 2012.

LABRES, Jair; SANTOS, Rael F. Jazz-bands no Brasil. In: SIMPÓSIO NACIONAL DE HISTÓRIA, 26., 2011. São Paulo. Anais... São Paulo: ANPUH, 2011. Disponível em: http://www.snh2011.anpuh.org/resources/ anais/14/1308176626_ARQUIVO_JAZZBANDSNOBRA SIL\%28versaofinalanpuh\%29.pdf > . Acesso em: 03 de janeiro de 2012.

MAFFESOLI, Michel. A contemplação do mundo. Porto Alegre: Artes e Ofícios, 1995.

. 0 tempo das tribos. Rio de Janeiro:

Forense-Universitária, 1987.

. Sobre o nomadismo: vagabundagens pós-

modernas. Rio de Janeiro: Record, 2001.

MCAAN, Brian. A bossa nova e a influência do blues.

Tempo, Rio de Janeiro, v. 14, n. 28, p. 101-122, 2010,

MOTTA, Nelson. Noites Tropicais. Rio de Janeiro:

Objetiva, 2000.

MUGGIATI, Robert. 0 que é jazz? São Paulo:

Brasiliense, 1999.

NAPOLITANO, Marcos. História e música: história cultural da música popular. Belo Horizonte: Autêntica, 2002.

NEGUS, Keith. Géneros musicales y la cultura de las multinacionales. Barcelona: Paidós, 2005.

OBICI, Giuliano. Condições da escuta: mídias e territórios sonoros. Rio de Janeiro: Ed. 7 Letras, 2008.

SCARABELOT, André Luis. Música brasileira e jazz. Revista Art \&. São Paulo, 2012. Disponível em: < http://www.revista.art.br/site-numero-03/ trabalhos/07.htm >. Acesso em: 12 jan. 2012.
SIMMEL, Georg. Questões fundamentais da

Sociologia. Rio de Janeiro: Jorge Zahar Editor, 2006.

SOUZA, Tarik et al. Brasil musical. Rio de Janeiro: Art Bureau, 1988.

SODRÉ, Muniz. As estratégias sensíveis: afeto, mídia e política. Petrópolis, RJ: Vozes, 2006.

STRAW, Will. Scenes and Sensibilities. E-Compós, Brasília, n. 6, ago. 2006. Disponível em: < http://www. compos.org.br/e-compos > . Acesso em: 27 out. 2011.

TINHORÃO, José R. Pequena história da música popular: da modinha à lambada. 6. ed. São Paulo: Art Editora, 1991. 
New Orleans is not here?

\section{Abstract}

Taking as reference not only the work of Negus, Maffesoli, Deleuze, Guattari, Bourdieu, and Straw, but also research conducted during 2011 and 2012 (consisting in the selection and analysis of press materials in traditional and alternative media, organization of interviews with jazz musicians and agents, and field work carried out in strategic venues), the aim of this article was to assess: a) whether a Rio de Janeiro jazz scene has been consolidated in the past two years; b) and if "musicability" and "street culture" are still continuing to produce social mobilization in that city.

\section{Keywords}

Communication. Urban Culture. Music.

Jazz. Sociability.

\section{¿New Orleans no es aquí?}

\section{Resumen}

Tomando como referencia no solamente las obras de Negus, Maffesoli, Deleuze, Guattari, Straw y Bourdieu, pero también el estudio realizado en 2011 e 2012 (que ha consistido en investigación y selección de materias vehiculadas el la prensa tradicional y alternativa en los últimos dos años, organización de entrevistas seme-estructuradas con los atores, así como ejecución de un trabajo de campo en sitios estratégicos), el objetivo fue evaluar en este trabajo: a) si, realmente, está se consolidando en Rio de Janeiro, en los últimos dos años, una escena del jazz; b) y si la "musicabilidad" y la "cultura de las calles" continúan generando gran movilización social en esta ciudad.

\section{Palabras claves}

Comunicación. Cultura Urbana. Música. Jazz. Sociabilidad. 


\section{Expediente}

A revista E-Compós é a publicação científica em formato eletrônico da Associação Nacional dos Programas de Pós-Graduação em Comunicação (Compós). Lançada em 2004, tem como principal finalidade difundir a produção acadêmica de pesquisadores da área de Comunicação, inseridos em instituições do Brasil e do exterior.

\section{E-COMPÓS I www.e-compos.org.br I E-ISSN 1808-2599}

Revista da Associação Nacional dos Programas

de Pós-Graduação em Comunicação.

Brasília, v.15, n.2, maio/ago. 2012.

A identificação das edições, a partir de 2008 ,

passa a ser volume anual com três números.

\section{CONSELHO EDITORIAL}

Afonso Albuquerque, Universidade Federal Fluminense, Brasil Alberto Carlos Augusto Klein, Universidade Estadual de Londrina, Brasil Álvaro Larangeira, Universidade Tuiuti do Paraná, Brasi André Luiz Martins Lemos, Universidade Federal da Bahia, Brasil Ângela Freire Prysthon, Universidade Federal de Pernambuco, Brasil Angela Cristina Salgueiro Marques, Faculdade Cásper Líbero (São Paulo), Brasil Antonio Roberto Chiachiri Filho, Faculdade Cásper Líbero, Brasil Arthur Autran Franco de Sá Neto, Universidade Federal de São Carlos, Brasil Benjamim Picado, Universidade Federal Fluminense, Brasil César Geraldo Guimarães, Universidade Federal de Minas Gerais, Brasil Cristiane Freitas Gutfreind, Pontifícia Universidade Católica do Rio Grande do Sul, Brasil

Denilson Lopes, Universidade Federal do Rio de Janeiro, Brasil Eduardo Peñuela Cañizal, Universidade Paulista, Brasi Eduardo Vicente, Universidade de São Paulo, Brasil Eneus Trindade, Universidade de São Paulo, Brasil Florence Dravet, Universidade Católica de Brasília, Brasil Gelson Santana, Universidade Anhembi/Morumbi, Brasil Gislene da Silva, Universidade Federal de Santa Catarina, Brasil Guillermo Orozco Gómez, Universidad de Guadalajara Gustavo Daudt Fischer, Universidade do Vale do Rio dos Sinos, Brasil Hector Ospina, Universidad de Manizales, Colômbia Herom Vargas, Universidade Municipal de São Caetano do Sul, Brasil Inês Vitorino, Universidade Federal do Ceará, Brasil Jay David Bolter, Georgia Institute of Technology Jeder Silveira Janotti Junior, Universidade Federal de Pernambuco, Brasil John DH Downing, University of Texas at Austin, Estados Unidos José Afonso da Silva Junior, Universidade Federal de Pernambuco, Brasil José Carlos Rodrigues, Pontifícia Universidade Católica do Rio de Janeiro, Brasi José Luiz Aidar Prado, Pontifícia Universidade Católica de São Paulo, Brasil Kelly Cristina de Souza Prudêncio, Universidade Federal do Paraná, Brasil. Laan Mendes Barros, Universidade Metodista de São Paulo, Brasil
Lance Strate, Fordham University, USA, Estados Unidos

Lorraine Leu, University of Bristol, Grã-Bretanha

Lucia Leão, Pontifícia Universidade Católica de São Paulo, Brasil

Malena Segura Contrera, Universidade Paulista, Brasil

Márcio de Vasconcellos Serelle, Pontifícia Universidade Católica de Minas Gerais, Brasil

Maria Aparecida Baccega, Universidade de São Paulo e Escola Superior de Propaganda e Marketing, Brasil

Maria Ataide Malcher, Universidade Federal do Pará, Brasi

Maria das Graças Pinto Coelho, Universidade Federal do Rio Grande do Norte, Brasil

Maria Immacolata Vassallo de Lopes, Universidade de São Paulo, Brasil Maria Luiza Martins de Mendonça, Universidade Federal de Goiás, Brasi Mauro de Souza Ventura, Universidade Estadual Paulista, Brasil Mauro Pereira Porto, Tulane University, Estados Unidos Mirna Feitoza Pereira, Universidade Federal do Amazonas, Brasil Nilda Aparecida Jacks, Universidade Federal do Rio Grande do Sul, Brasil Osvando J. de Morais, Universidade de Sorocaba, Brasil Potiguara Mendes Silveira Jr, Universidade Federal de Juiz de Fora, Brasil Renato Cordeiro Gomes, Pontifícia Universidade Católica do Rio de Janeiro, Brasil Robert K Logan, University of Toronto, Canadá

Ronaldo George Helal, Universidade do Estado do Rio de Janeiro, Brasil Rose Melo Rocha, Escola Superior de Propaganda e Marketing, Brasil Rossana Reguillo, Instituto de Estudos Superiores do Ocidente, Mexico Rousiley Celi Moreira Maia, Universidade Federal de Minas Gerais, Brasil Sebastião Guilherme Albano da Costa, Universidade Federal do Rio Grande do Norte, Brasil

Simone Maria Andrade Pereira de Sá, Universidade Federal Fluminense, Brasil Tiago Quiroga Fausto Neto, Universidade de Brasília, Brasil Suzete Venturelli, Universidade de Brasília, Brasil Valerio Fuenzalida Fernández, Puc-Chile, Chile Veneza Mayora Ronsini, Universidade Federal de Santa Maria, Brasil Vera Regina Veiga França, Universidade Federal de Minas Gerais, Brasil

\section{COMISSÃO EDITORIAL}

Adriana Braga I Pontifícia Universidade Católica do Rio de Janeiro, Brasil

Felipe Costa Trotta I Universidade Federal Fluminense, Brasi

CONSULTORES AD HOC

Adriana Amaral, Universidade do Vale do Rio dos Sinos, Brasil

Ana Carolina Escosteguy, Pontifícia Universidade Católica do Rio Grande do Sul, Brasi Claudia Azevedo, Universidade Federal do Estado do Rio de Janeiro, Brasil Gisela Castro, Escola Superior de Propaganda e Marketing, Brasil Luis Queiroz, Universidade Federal da Paraíba, Brasil Rodrigo Carreiro, Universidade Federal de Pernambuco, Brasil EDIÇÃO DE TEXTO E RESUMOS I Susane Barros SECRETÁRIA EXECUTIVA I Juliana Depiné EDITORAÇÃO ELETRÔNICA I Roka Estúdio TRADUÇÃo I Sieni Campos
COMPÓS I www.compos.org.br

Associação Nacional dos Programas de Pós-Graduação em Comunicação

Presidente

Julio Pinto

Pontifícia Universidade Católica de Minas Gerais, Brasil juliopinto@pucminas.br

Vice-presidente

Itania Maria Mota Gomes

Universidade Federal da Bahia, Brasil

itania@ufba.br

Secretária-Geral

Inês Vitorino

Universidade Federal do Ceará, Brasil

inesvic@gmail.com 